Gut, 1971, 12, 709-712

\title{
Small bowel in typhoid fever
}

\author{
H. K. CHUTtANI, K. JAIN, AND R. C. MISRA ${ }^{1}$
}

From the Gastroenterology Unit, Department of Medicine, Maulana Azad Medical College, and Associated Irwin and G.B. Pant Hospitals, New Delhi-1, India

SUMmaRY Twenty-eight patients with typhoid fever and one patient with paratyphoid fever were subjected to intestinal function tests (faecal fat and D-xylose) and jejunal biopsy soon after recovery from the acute phase of the disease in order to assess the residual functional and morphological status of the small bowel. The results indicate that almost 50\%(14/29) initially had defective D-xylose absorption which recovered rapidly. No patient had steatorrhoea. Jejunal biopsies of eight patients out of 22 showed increased chronic cell infiltration; there was, however, no specific lesion. It appears that intestinal injury following salmonellosis results only in mild functional derangement of the bowel which recovers rapidly.

Salmonella typhi and Salmonella paratyphi infections still remain a serious communicable disease in this part of the world and are known to involve small bowel extensively. The extent of functional damage which may occur during the acute phase of the disease is difficult to assess as the patients are usually quite ill and on restricted diets. It was thought worthwhile to assess the morphological status of the small bowel soon after recovery from the acute phase of the disease to find out if any residual damage persisted and if some of these patients pass into a state of chronic malabsorption.

\section{Patients and Methods}

The study comprised 28 patients with typhoid fever and one with paratyphoid fever. There were 23 males and six females. The age range was 13 to 30 years (mean $19 \pm 4.6$ years). Detailed clinical examination was carried out and recorded.

The diagnosis was based on isolation of the causative organism and/or a serological test showing a rising titre of antibodies in the serum. In the 29 patients, Salmonella typhi was isolated in 23 and Salmonella paratyphi in one patient. In five patients the diagnosis was based on a rising titre of Widal tests with clinical features suggestive of this condition. All the patients were put on chloramphenicol therapy.

To assess the functional and morphological status of the small bowel, the following tests were performed during the first week of the afebrile period.

${ }^{1}$ Address for correspondence: Dr R. C. Misra, Nutritional and Intestinal Unit, The General Hospital, Birmingham B4 6NH.

Received for publication 24 June 1971.
D-XYLOSE TEST

Five $\mathrm{g}$ of D-xylose was used. A five-hour urinary excretion of less than $1.0 \mathrm{~g}$ was considered abnormal. Patients in whom the test was found to be abnormal initially had a repeat test after one week, which was performed when patients were passing urine freely and blood urea was within normal limits.

\section{FAECAL FATS}

The patients were kept on a $100 \mathrm{~g}$ fat diet for three days, after which a three-day continuous collection of stools was made while the patients remained on this diet. Faecal fats were estimated by the method of van de Kamer, ten Bokkel Huinink, and Weyers (1949). A faecal fat excretion of more than $6 \mathrm{~g}$ per 24 hours was taken to be abnormal.

\section{JEJUNAL BIOPSY}

Biopsies were undertaken in only those patients who freely volunteered to participate in the study after its purpose and possible hazards had been explained. Jejunal biopsies were performed from the upper third of the jejunum with radiological localization of the biopsy capsule. Biopsy specimens were transferred from the capsule to the fixative within three minutes, and care was taken to ensure their proper orientation. After fixation the specimens were serially sectioned to obtain vertically orientated villi.

\section{RADIOLOGICAL EXAMINATION}

Barium meal examination of the small bowel was carried out with non-flocculable barium (Micropaque) and serial radiographs were taken to rule out any other gastrointestinal disease. 


\section{Results}

CLINICAL PROFILE

At the time of admission to hospital all the patients were acutely ill. Duration of fever at admission ranged from two to 30 days (mean $10 \pm 6.6$ days). Frontal headache, abdominal pain, constipation, and general malaise were the prominent symptoms. Six patients complained of diarrhoea without blood or mucus. In one patient there was a history of melaena before admission. Ten patients were delirious on admission. Physical examination revealed splenomegaly in 25 and hepatomegaly in 10 patients.

\section{D-XYLOSE EXCRETION TEST}

The urinary D-xylose excretion was found to be subnormal in 14 out of 29 patients. The test was repeated after one week in 12 of those patients in whom it was found to be subnormal. There was an appreciable increase in the urinary excretion of D-xylose in all the patients (Fig. 1) and this was statistically significant $(t=11.5$ for $11 \mathrm{df}: \mathrm{P}<0.001)$.

\section{FAECAL FAT EXCRETION}

The average faecal fat excretion ranged from 0.57 to $5.2 \mathrm{~g}$ per 24 hours, the average being $2.87 \pm 1.17 \mathrm{~g}$ per 24 hours. In no patient was it above the normal limits.

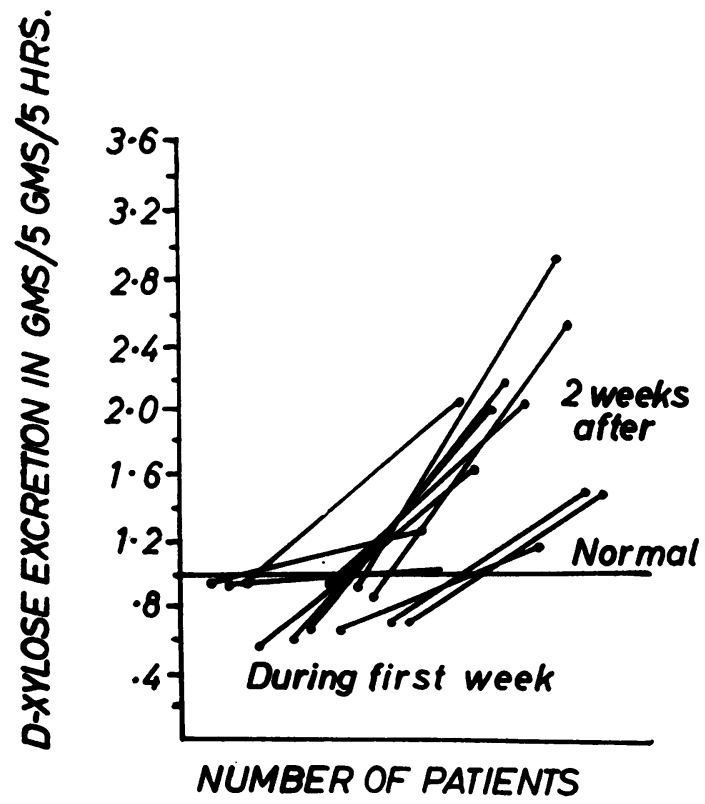

Fig. 1. Initial and repeat $D$-xylose test in 12 patients.

\section{JEJUNAL BIOPSY}

Biopsy from the small intestine was performed in 26 patients and adequate material for interpretation was available in 22 patients.

Complications such as bowel perforation or haemorrhage were not encountered in any of the patients. The so-called 'post-biopsy fever' was seen in two patients. The findings have been broadly grouped in three categories: normal (14), normal with increased infiltration (6), and abnormal biopsies (2).

Normal biopsies were obtained in 14 patients. The villi were tall and slender. The epithelium was of columnar type with basal nuclei. Cellular infiltrate in the lamina propria consisted of lymphocytes, monocytes, and plasma cells (Fig. 2).

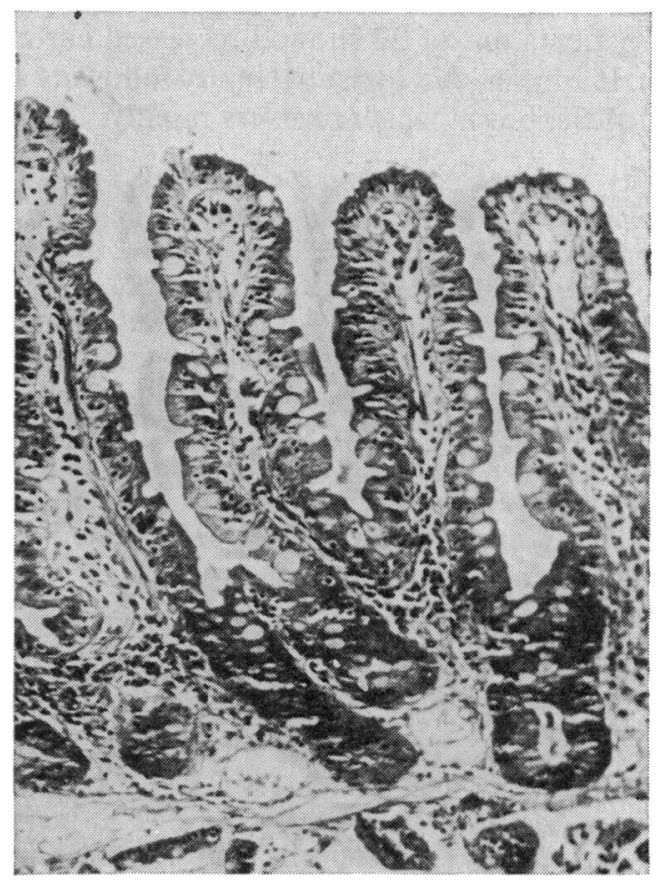

Fig. 2. Normal jejunal biopsy.

In six patients the biopsies showed mild borderline abnormalities, which consisted of increase in cellular infiltration with normal villous architecture. The mixed type of infiltrate was more compact in the basal portion of the mucosa and around the crypts of Galeazzi-Lieberkuhn and gradually became less towards the villous core. Predominant cells were mononuclear histiocytes and lymphocytes. Biopsies from two other patients showed that villi were of variable length, the majority being short and broad. Normal scalloping of the villi was absent. The crypts were mostly rounded. The surface epithelium showed increased infiltration and at places it was 


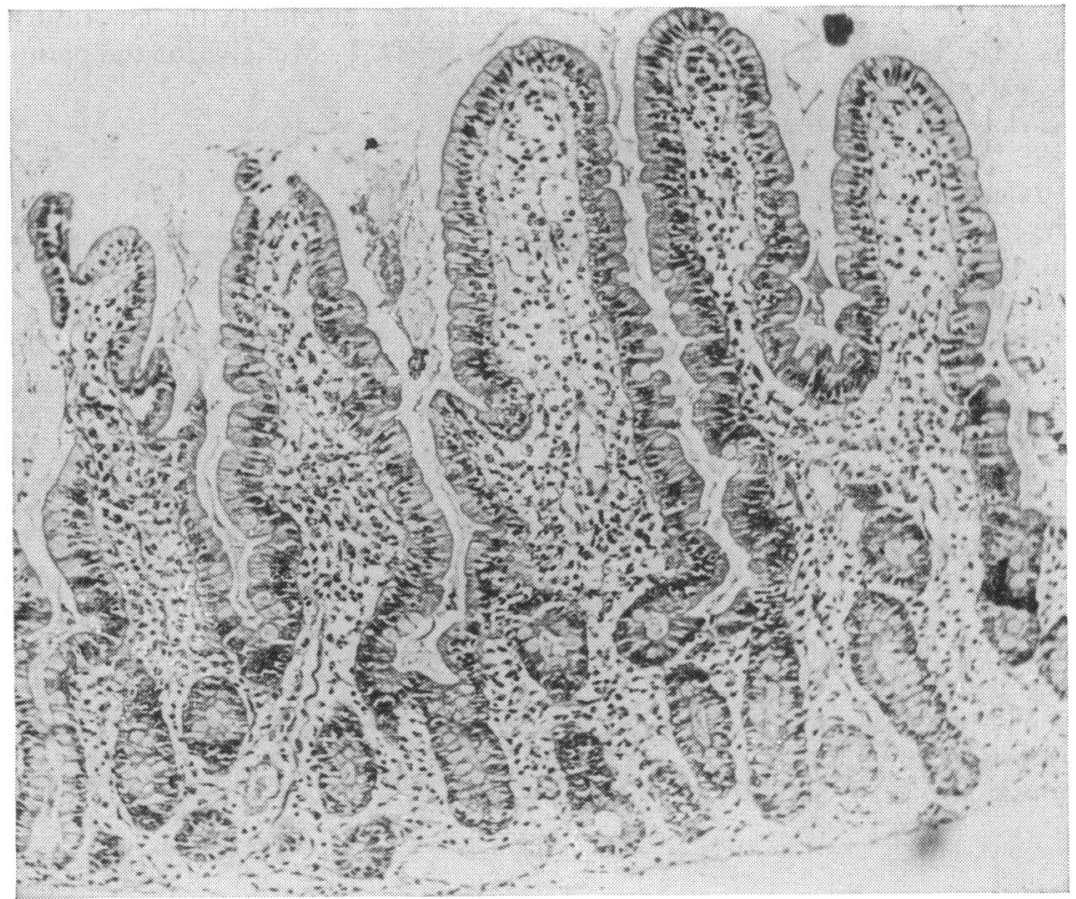

Fig. 3. Jejunal biopsy showing shortening and blunting of villi with dense cellular infiltration.

cuboidal. Cellular infiltrate on the whole was more dense (Fig. 3).

\section{RADIOLOGICAL EXAMINATION}

The barium meal examination was performed in 28 patients. In 24 patients no abnormality was seen. In one patient prominent mucosal folds were observed. Flocculation and segmentation of the barium was seen in three patients.

\section{Discussion}

The present study indicates that functional impairment occurs early in the disease. The urinary D-xylose excretion test performed in the first week of the afebrile period showed that almost half of the patients (14/29) had faulty absorption. Recovery was also rapid as the repeat test done seven days after the first test showed complete recovery in all the patients. Shamma'a and Ghazanfar (1960) in their study of five patients had also reported impaired D-xylose absorption. It is well known that transient malabsorption occurs in some other acute bowel infections also due to specific (cholera) or nonspecific agents (Lindenbaum, 1965).

In the present study no patient was found to have developed steatorrhoea. This may indicate that functional impairment is only borderline, as fats are known to be absorbed all along the small intestine, whereas D-xylose absorption occurs mainly in the upper small bowl (Fisher and Parson, 1949; Crane, 1960). Booth (1963) has reported that an isolated proximal small bowel resection may not lead to steatorrhoea.

Proximal small bowel biopsies in 22 patients failed to exhibit any specific or notable abnormality. Most of the patients (14/22) had normal mucosa. Minor morphological abnormalities seen in the remaining eight patients could well be seen in a normal population in the tropics (Misra, Krishnan, Ramalingaswami, and Chuttani, 1967; Baker and Mathan, 1968). However, dense infiltration of the mucosa with mononuclear cells could well be a non-specific response to salmonellosis. The definite enteritis and granulomatous reaction reported by Sprinz, Gangarosa, Williams, Hornick, and Woodward (1966) in a study of six volunteer subjects was not encountered. Our patients, however, were different from those studied by Sprinz et al (1966). Their subjects were healthy controls belonging to a nonimmune population and were given a heavy concentrated oral dose of typhoid bacilli. They themselves have noted that the magnitude of the challenge dose possibly influenced the character of the histological response. Our patients naturally acquired the disease with slow ingestion of probably a lesser 
number of organisms, and belong to a population where typhoid fever is endemic. The biopsies done by Sprinz et al (1966) in some patients were at the height of the disease, whereas we have biopsied them only after the fever has subsided.

Unlike Sprinz et al (1966) we have not found any positive correlation between the severity of systemic clinical symptoms, leucopenia, and the severity of the histological lesion. There was also no correlation between clinical status and functional or histological alterations observed in our cases.

It appears that there are no specific histopathological alterations in the mucosa of the upper small bowel obtained by peroral intestinal biopsy capsule and that the acute injury due to salmonellosis results only in mild functional derangement of the small bowel which recovers rapidly.

We are indebted to the Director-Principal, Maulana Azad Medical College, for permission to publish this paper, to the Department of Microbiology for their help. Sri Shakti Chandra was most helpful in handling and processing the biopsies. Sri G. S. Sarin and Sudhir Kumar were helpful in the laboratory. We are obliged to Sri D. P. Mohalla for the photographs.

References

Baker, S. J., and Mathan, V. I. (1968). Syndrome of tropical sprue in South India. Amer. J. clin. Nutr., 21, 984-993.

Booth, C. C. (1963). Absorption from the small intestine $\mathrm{Sci}$. Basis Med. Ann. Rev, pp. 171-196.

Crane, R. K. (1950). Intestinal absorption of sugars. Physiol. Rev., 40, 789-825.

Fisher, R. B., and Parson, D. S. (1949). A preparation of surviving rat small intestine for the study of absorption. J. Physiol. (Lond.), 110, 36-46.

van de Kamer, J. H., ten Bokkel Huinink, H., and Weyers, H. A. (1949). Rapid method for the determination of fat in feces. J. biol. Chem., 177, 347-355.

Lindenbaum, J. (1965). Malabsorption during and after recovery from acute intestinal infection. Brit. med. J., 2, 326-329.

Misra, R. C., Krishnan, N., Ramalingaswami, V., and Chuttani, H. K. (1967). Tropical sprue in Northern India. Scand. J. Gastroent., 2, $192-199$.

Shamma'a, M. H., and Ghazanafar, S. A. S. (1960). D-xylose test in enteric fever, cirrhosis liver and malabsorptive states. Brit.med. $J ., 2,836-838$.

Sprinz, H., Gangarosa, E. J., Williams, M., Hornick, R. B., and Woodward, T. E. (1966). Histopathology of the upper small intestines in typhoid fever. Biopsy study of experimental disease in man. Amer. J. dig. Dis., 11, 615-629. 